\section{THE ALIGNMENT BETWEEN \\ THIRD-GRADE PRIMARY \\ SCHOLL SCIENCE TEXTBODKS \\ AND CURRICULUM STANDARDS \\ IN CHINA AND JAPAN}

J O U R N A L

$\mathrm{OF} \bullet \mathrm{B}$ A L T I C

$S$ C I E N C E

EDUCATION

\section{Lihui Sun, Liangbo Li}

\section{Introduction}

Textbooks play an irreplaceable role in promoting students' mastery of scientific knowledge and organization of learning activities. Besides, textbooks are the factor affecting students' academic performance (Aldahmash et al., 2016; Andersen, 2020; Polikoff, 2015), and the guarantee for teachers to implement curriculum standards (Hill, 2001), so it is necessary to examine the textbooks (Vojír \& Rusek, 2021). Under the standards-based reform, standards become the important basis of measurement, guide the curriculum development and classroom teaching, and put forward clear goals and expectations for teachers to improve teaching quality and students to improve their academic performance (Troia et al., 2018). Improving the alignment among various components of the education system is of great significance for ensuring the quality of education, achieving the expected goals, and carrying out the evaluation work (Fulmer et al., 2018; Newton \& Kasten, 2013; Qhibi et al., 2020). Therefore, as the educational components, it is necessary to achieve a high degree of alignment between textbooks and curriculum standards.

Under the background of the new round of curriculum reform, it was pointed out that the curriculum standards are the basis for the compilation of textbooks in China (Ministry of Education, 2001). In 2017, the new version of primary school science curriculum standard was promulgated in China (Ministry of Education, 2017), then the new primary school science textbooks were published by various presses. However, it is not clear whether the new primary school science textbooks really follow the requirements of the curriculum standard and maintain a high alignment level with the curriculum standard. As a neighbour of China, the reform based on curriculum standards also started in Japan and achieved some results (Ministry of Education, Culture, Sports, Science and Technology-Japan (MEXT), 2019). Especially in the field of science education, Japanese students have performed well in international tests such as The Program for International Student Assessment (PISA) and Trends in International Mathematics and Science Study (TIMSS) in recent years (MEXT, 2019; MEXT, 2020). Since China and Japan have certain similarities in
Abstract. This study applied the Porter's alignment model to construct a localized two-dimensional framework based on Anderson's taxonomy. The research chose the third-grade primary school science textbooks from two representative presses in China and Japan, coded the textbooks and curriculum standards, calculated the alignment level between the textbooks of the two presses and their corresponding curriculum standards, and discussed the alignment level from the topic, cognitive demand, and emphasis. The results show that the $B$ version in Japan is significantly aligned with the Japanese curriculum standard, but the A version in China does not have significant alignment with the Chinese curriculum standard. Besides, a common problem is that the ratios of life science in sample science textbooks both exceed the requirements of the curriculum standards, and the problems of exceeding the standard in cognitive demand and not highlighting the key points also need to be concerned. This study provides ideas and references for countries with similar educational situations to study the compilation of science textbooks and fills up the deficiency of the international comparison of the alignment between primary school science textbooks and curriculum standards by using the alignment model.

Keywords: alignment evaluation, content analysis, curriculum standards, primary school, science textbooks

Lihui Sun, Liangbo Li Tianjin University, P. R.China 
educational background, such as both countries have nine-year compulsory education and require children to enter primary school at the age of six (MEXT, 2015; The National People's Congress, 2019; Tian, 2015), comparing the alignment of primary school science textbooks and curriculum standards in two countries, may be helpful to obtaining findings that can provide some reference for the development of primary school science textbooks.

\section{Alignment Models}

In order to examine the level of alignment among educational components such as standards, assessment and so on, researchers have established different alignment methods with different characteristics. Webb (1999) defined alignment as the degree of alignment between expectation and assessment. The model he established was evaluated from four dimensions, categorical concurrence, depth-of-knowledge consistency, range-of-knowledge correspondence, and balance of representation. Porter's alignment model established the Porter's alignment formula, from two dimensions of the topic and cognitive demand to construct the framework (Porter, 2002; Porter et al. 2007). Porter's model can be applied to international comparison and can be analysed and compared from the overall alignment index and the two dimensions respectively (Liu et al., 2009). Achieve model was used to analyse the alignment between the evaluation project and the standards from the aspects of content centrality and performance centrality, the challenge of the evaluation project, and the balance and range of knowledge (Rothman et al. 2002).

In the existing research on the application of alignment models, most researchers prefer to analyse the alignment between academic assessment and curriculum standard. For example, based on the Webb's model, Webb (1999) analysed the alignment between math and science assessments and standards in basic education in four states of the United States, and found that there were great differences among different states. Fitzpatrick et al. (2015) conducted a study on the alignment between the assessment and curriculum standard of therapeutics courses in Canadian higher education and found that the results were unsatisfactory. Based on the Porter's model, Liang and Yuan (2008) and Liu et al. (2009) both studied the degree of alignment between the standardized test and the curriculum standards of middle school physics in China, and the data both proved the poor alignment level. Similarly, Lu and Liu (2012) tested the alignment between middle school biology standardized tests and curriculum standard in China and found that there was no significant alignment between tests and curriculum standard in four provinces. Contino (2013) analysed the alignment of examinations and curriculum standard of earth science in New York, and the results also showed that the alignment was not ideal.

In addition, there have been less studies about the alignment between teaching materials and curriculum standards. Qhibi et al. (2020) conducted a study on alignment between content standard and practice materials in high school mathematics and concluded that the results were acceptable but needed further adjustment. Polikoff et al. (2015) tested the alignment of primary school mathematics textbooks and curriculum standards and found that the alignment index was not high. It can be found that in the existing studies, there is insufficient research on the alignment of teaching materials with curriculum standards, and the research subjects mostly focus on mathematics.

\section{Alignment Between Science Textbooks and Curriculum Standards}

Science education has attracted more and more international attention, and the cultivation of scientific literacy has become an important part of education in various countries (Çakici, 2012). Science textbooks are the indispensable part of science education, so researchers have explored science textbooks from different perspectives (Gilavand et al., 2016; Røthing,2017; Yacoubian et al., 2017).

With the deepening of standards-based reform, some researchers began to pay attention to the relationship between science textbooks and curriculum standards and tried to evaluate whether science textbooks meet the requirements of standards. Although many science textbook publishing houses have claimed that their books were written according to the curriculum standards, some research results indicated that the science textbooks still did not meet the requirements of the curriculum standards. For example, aiming at the content of the nature of science in science textbooks, Abd-El-Khalick et al. (2008) and Li et al. (2020) scored the middle school chemistry textbooks and the middle school physics textbooks respectively, the results show that the textbooks were not well aligned with the current science curriculum standards and science education reform documents. As for the content of the science inquiry in science textbooks, Aldahmash et al. (2016) analysed the science inquiry of several science textbooks in Saudi Arabia and found that textbooks did not contain all the features of inquiry, as they were 
not aligned with the National Science Education Standard. Similarly, Li et al. (2018) pointed out that the inquiry activities in China's five versions of the physics textbooks were also not in line with the requirement of paying attention to the importance of scientific inquiry in science education advocated in the science curriculum standard.

Although some researchers have pointed out that some of the current science textbooks were not aligned with the standards in some respects, it was found that most of the current related studies focus on the middle school science textbooks, but less on the primary school science textbooks. In addition, there is a lack of research on applying the alignment models to analyse the alignment level between science textbooks and the standards on the whole, so the study of the alignment between science textbooks and standards needs to be further strengthened.

\section{Research Aim and Research Questions}

The existing research on science textbooks mostly started from a certain part of the content of textbooks, such as the scientific inquiry activities in textbooks, to explore whether its setting is in line with the concept advocated by curriculum standards. However, there is less attention on the setting of curriculum standards, and there is also a lack of comparative research on the alignment between science textbooks and curriculum standards in different countries by using the model. This study not only aims to discuss the compilation of science textbooks from the perspective of curriculum standards by calculating the alignment level between curriculum standards and science textbooks, but also aims to understand the alignment level between science textbooks and curriculum standards in different countries through international comparative research, so as to achieve the purpose of international mutual reference.

In addition, children's intelligence in primary school has experienced a transition from the main form of concrete image thinking to the main form of abstract logic thinking, and the third and fourth grades are just the key period of transition (Lin, 2011). Therefore, this study takes the third-grade primary school science textbooks and curriculum standards in China and Japan as the analytical material, carries out comparative analysis and discussion on the alignment between primary school science textbooks and curriculum standards, and identifies the following research questions:

1. What is the alignment level between the third-grade primary school science textbook of the A version in China and the Chinese science curriculum standard?

2. What is the alignment level between the third-grade primary school science textbook of the $B$ version in Japan and the Japanese science curriculum standard?

3. What references and suggestions can be provided for the compilation of primary school science textbooks through the comparative study between China and Japan?

\section{Research Methodology}

\section{General Background}

In this study, the Porter's alignment model was selected as the instrument and adjusted in its localization. Based on this framework, content analysis and coding were carried out for the text contents of the Chinese and Japanese third-grade primary school science textbooks and their corresponding curriculum standards. The coding results of the two countries were substituted into the Porter's alignment formula to obtain the alignment level, then the results were compared and discussed.

\section{Selection of Materials for Analysis}

In order to examine the alignment level between textbooks and curriculum standards, the curriculum standards and textbooks need to be coded. The new science curriculum standards for primary schools in China and Japan were both released in 2017, and the learning objectives and contents of each grade were clearly defined in the standards. Since the description of the learning objectives was detailed and with high operability, such as "Through the observation, describing the hot air rising phenomenon", so the learning objectives in the curriculum standards became the reference for coding.

For the selection of textbooks, the third-grade primary school science textbook (version A) published by the Chinese publishing house $A$, and the third-grade primary school science textbook (version $B$ ) published by the 
Japanese publishing house B were chosen to be the materials of the study. Both versions of the textbooks are now widely used in both countries, and two publishing houses both have claimed to comply with new science curriculum standards for primary schools. The two publishers also provided reference guides for teachers when published the textbooks, the teaching objectives and teaching hours of each lesson were defined in them, such as "Students can list the examples of the compressed air used in production and life". The teaching objectives formed the corresponding relationship with the learning objectives in the curriculum standards, so the teaching objectives in the textbooks became the reference for coding.

\section{Instrument}

The Porter's alignment model was chosen to be the instrument to detect the alignment level between a textbook and its corresponding curriculum standard. In this model, a two-dimensional table about the "topic" and the "cognitive demand" was established (Porter, 2002; Porter et al. 2007), so not only the alignment index between the tested textbook and the curriculum standard was clear, but also the alignment of the textbook on topic and cognitive demand were presented respectively. Through the adjustment to the localization of the model, the "topic" dimension was divided into physical science, life science, and earth and space science. The main reason is that the two countries have certain commonalities in the topic division after referring to the specific content of primary school science curriculum standards and textbooks in China and Japan. In the cognitive demand dimension, it was divided into six levels: remember, understand, apply, analyse, evaluate, and create. This classification method was referred to the classification of cognitive process dimension in Anderson's taxonomy (Anderson \& Krathwohl, 2001), which was built on Bloom's taxonomy. Anderson further subdivided the six levels into 19 specific items. The specific division is shown in Table 1. This classification method was chosen because some researchers had adjusted the Porter's alignment model and analysed Chinese science standardized tests on this basis (Liu et al. 2009), so it can be considered to be scientific and applicable. By dividing the dimensions of "topic" and "cognitive demand", a $3 \times 6$ table was formed.

Table 1

Classification of Cognitive Process Dimension in Anderson's Taxonomy

\begin{tabular}{|c|c|c|}
\hline $\begin{array}{l}\text { Cognitive } \\
\text { demand }\end{array}$ & Explanation & Specific items \\
\hline Remember & Extract relevant information from long-term memory. & Recognize, Recall \\
\hline Understand & Construct meaning from oral, written, and graphic information. & $\begin{array}{l}\text { Interpret, Exemplify, Classify, Summa- } \\
\text { rize, Infer, Compare, Explain }\end{array}$ \\
\hline Apply & Execute or applying a program in a particular situation. & Execute, Implement \\
\hline Analyse & $\begin{array}{l}\text { Decompose the material into components and determine the relationship } \\
\text { between each part and the overall relationship. }\end{array}$ & Differentiate, Organize, Attribute \\
\hline Evaluate & Make judgments based on criteria. & Check, Critique \\
\hline Create & $\begin{array}{l}\text { Integrate elements into a whole with unified functions or reorganize ele- } \\
\text { ments into a new structure. }\end{array}$ & Generate, Plan, Produce \\
\hline
\end{tabular}

\section{Procedures}

After the framework was determined, the text content of curriculum standards and textbooks was analysed and coded. The two coders employed in this study are both researchers engaged in scientific education research and proficient in Chinese and Japanese. They first discussed the framework and clarified the details of the coding. Secondly, two coders coded the curriculum standards and textbooks independently. Thirdly, the two coders' respective coding results were calculated by Kendall correlation coefficient to ensure the scientific results. Finally, they discussed each item together, especially the differences, until a consensus was reached.

Based on the coding results, this study analysed the alignment level between primary school science textbooks and curriculum standards in China and Japan. In order to find out the misalignment between the textbooks 
ISSN 1648-3898/Print/ THE ALIGNMENT BETWEEN THIRD-GRADE PRIMARY SCHIDL SCIENCE TEXTBIDKS AND

and the curriculum standards, the two versions of the textbooks were compared and discussed from the topic, cognitive demand, and emphasis.

\section{Data Analysis}

To calculate the alignment level of the coding results, the data was normalized to make the sum of the rows and columns of the two-dimensional table was 1, then the two-dimensional ratio tables of curriculum standards and textbooks were obtained (Porter et al., 2007). The data in the tables was substituted into Porter's alignment formula, and Porter's alignment index $\mathrm{P}$ was obtained. In the formula, P represents the Porter's alignment index, $n$ represents the number of cells in the two-dimensional table, $i$ represents a cell in the two-dimensional table, and $X$ and $Y$ represent two objects for alignment evaluating. In this study, they are the tables of the curriculum standards and the textbooks, respectively. Since the tables were normalized, the range of $P$ is 0 to 1 , and the larger the $P$ is, the higher the degree of alignment between the two objects is proved; conversely, the smaller the $\mathrm{P}$ is, the lower the degree of alignment is proved (Poter, 2002).

$$
P=1-\frac{\sum_{i=1}^{n}\left|X_{i}-Y_{i}\right|}{2}
$$

Since any two tables are likely to have a certain degree of alignment, it is necessary to find a statistically significant critical value to compare with the alignment index obtained by the Porter's alignment formula. After coding through the Matlab, two $3 \times 6$ two-dimensional tables of the textbook and curriculum standard were randomly accessed, the process was executed 20000 times to get the mean and standard deviation of $P$, and the statistically significant critical value at the 0.05 level was calculated. When the alignment index reaches the critical value, there is a statistically significant alignment between the textbook and curriculum standard (Liu et al., 2009). Next, the clustered column charts were formed to present the alignment from the dimensions of topic and cognitive demand, and the content maps were formed to present the alignment of emphasis.

\section{Research Results}

\section{Comparison of Alignment Index}

Table 2 presents the learning objectives of the Chinese curriculum standard and the teaching objectives of the $A$ version textbook in ratios separately. The number in each cell represented the ratio of the curriculum standard or textbook in each cognitive demand under each topic. Because of the normalization, the final sum of the part of the curriculum standard or the textbook was 1 .

\section{Table 2}

Learning Objectives of the Chinese Curriculum Standard and Teaching Objectives of the A Version Textbook in Ratios

\begin{tabular}{llccccccc}
\hline & Remember & Understand & Apply & Analyse & Evaluate & Create & Subtotal \\
\hline \multirow{3}{*}{$\begin{array}{lllllll}\text { Chinese curriculum } \\
\text { standard }\end{array}$} & Physical science & 0.190 & 0.167 & 0.071 & 0 & 0 & 0.024 & 0.452 \\
& Life science & 0.048 & 0.143 & 0 & 0 & 0 & 0 & 0.191 \\
& $\begin{array}{l}\text { Earth and space } \\
\text { science }\end{array}$ & 0.143 & 0.143 & 0.071 & 0 & 0 & 0 & 0.357 \\
& Subtotal & 0.381 & 0.453 & 0.142 & 0 & 0 & 0.024 & 1 \\
\hline \multirow{3}{*}{ A version textbook } & Physical science & 0.071 & 0.161 & 0.106 & 0 & 0 & 0.034 & 0.372 \\
& Life science & 0.137 & 0.158 & 0.037 & 0.014 & 0.007 & 0.020 & 0.373 \\
& $\begin{array}{l}\text { Earth and space } \\
\text { science }\end{array}$ & 0.113 & 0.093 & 0.032 & 0 & 0 & 0.018 & 0.256 \\
& Subtotal & 0.321 & 0.412 & 0.175 & 0.014 & 0.007 & 0.072 & 1 \\
\hline
\end{tabular}


Table 3 presents the learning objectives of the Japanese curriculum standard and the teaching objectives of the $B$ version textbook in ratios separately. Similar to Table 2 , data comparison could reflect the similarities and differences in the proportion distribution of various topics and cognitive demands between this version of textbook and its corresponding curriculum standard.

Table 3

Learning Objectives of the Japanese Curriculum Standard and Teaching Objectives of the B Version Textbook in Ratios

\begin{tabular}{|c|c|c|c|c|c|c|c|c|}
\hline & & Remember & Understand & Apply & Analyse & Evaluate & Create & Subtotal \\
\hline \multirow{3}{*}{$\begin{array}{l}\text { Japanese curricu- } \\
\text { lum standard }\end{array}$} & Physical Science & 0.175 & 0.227 & 0.175 & 0 & 0 & 0.021 & 0.598 \\
\hline & Life science & 0.083 & 0.113 & 0.062 & 0 & 0 & 0 & 0.258 \\
\hline & $\begin{array}{l}\text { Earth and space } \\
\text { science }\end{array}$ & 0.041 & 0.052 & 0.052 & 0 & 0 & 0 & 0.145 \\
\hline \multirow{5}{*}{$B$ version textbook } & Subtotal & 0.299 & 0.392 & 0.289 & 0 & 0 & 0.021 & 1 \\
\hline & Physical science & 0.103 & 0.189 & 0.162 & 0 & 0 & 0.081 & 0.535 \\
\hline & Life science & 0.105 & 0.168 & 0.088 & 0 & 0 & 0 & 0.361 \\
\hline & $\begin{array}{l}\text { Earth and space } \\
\text { science }\end{array}$ & 0.033 & 0.045 & 0.027 & 0 & 0 & 0 & 0.105 \\
\hline & Subtotal & 0.241 & 0.402 & 0.277 & 0 & 0 & 0.081 & 1 \\
\hline
\end{tabular}

The alignment index was obtained by substituting the data into the Porter's alignment formula, and significant critical value at the level of 0.05 was obtained through Matlab (Table 4). By comparing the alignment index of the two versions of textbooks with their corresponding critical value, it was found that the alignment index of the A version textbook (0.756) was lower than its critical value (0.779), indicating that there was no significant alignment between the $A$ version textbook and the Chinese curriculum standard. However, the alignment index of the B version textbook (0.837) was higher than its critical value $(0.776)$, indicating that the $B$ version textbook had significant alignment with the Japanese curriculum standard.

\section{Table 4}

Alignment between Two Versions of Textbooks and Their Curriculum Standards

\begin{tabular}{lcccc}
\hline & Mean & $\begin{array}{c}\text { Standard } \\
\text { deviation }\end{array}$ & Alignment index & Critical value \\
\hline $\begin{array}{l}\text { Alignment between the A version textbook and the Chinese curriculum } \\
\text { standard }\end{array}$ & 0.676 & 0.063 & 0.756 & 0.779 \\
$\begin{array}{l}\text { Alignment between the B version textbook and the Japanese cur- } \\
\text { riculum standard }\end{array}$ & 0.673 & 0.063 & 0.837 & 0.776 \\
\hline
\end{tabular}

\section{Comparison of Alignment from the Topic}

In order to more clearly present the ratios of each topic between the textbooks and the curriculum standards in China and Japan respectively, clustered column charts in Figure 1 were formed. In the figure, the abscissa represented the three topics, and the ordinate was the ratio of the topic to the whole content. It was found that between the ratio of the $A$ version with the Chinese curriculum standard in different topics exists obvious inconsistency. Life science had the lowest share in the curriculum standard but became the topic of the highest share in the textbooks. However, the B version and the Japanese curriculum standard were in the same order in the topic dimension, and the ratio gap of different topics was obvious, both highlighted the physical science as the key topic. In addition, an interesting common point was that the textbooks of two versions both set the topic beyond the curriculum standard in the topic of life science, and the ratio of the excess was relatively large. As a result, the topic of physical science and earth and space science could not meet the requirements of the curriculum standard. 


\section{Figure 1}

The Ratios of the Chinese Curriculum Standard (CCS) and the A Version Textbook, the Japanese Curriculum Standard (JCS) and the $B$ Version Textbook in the Topic Dimension

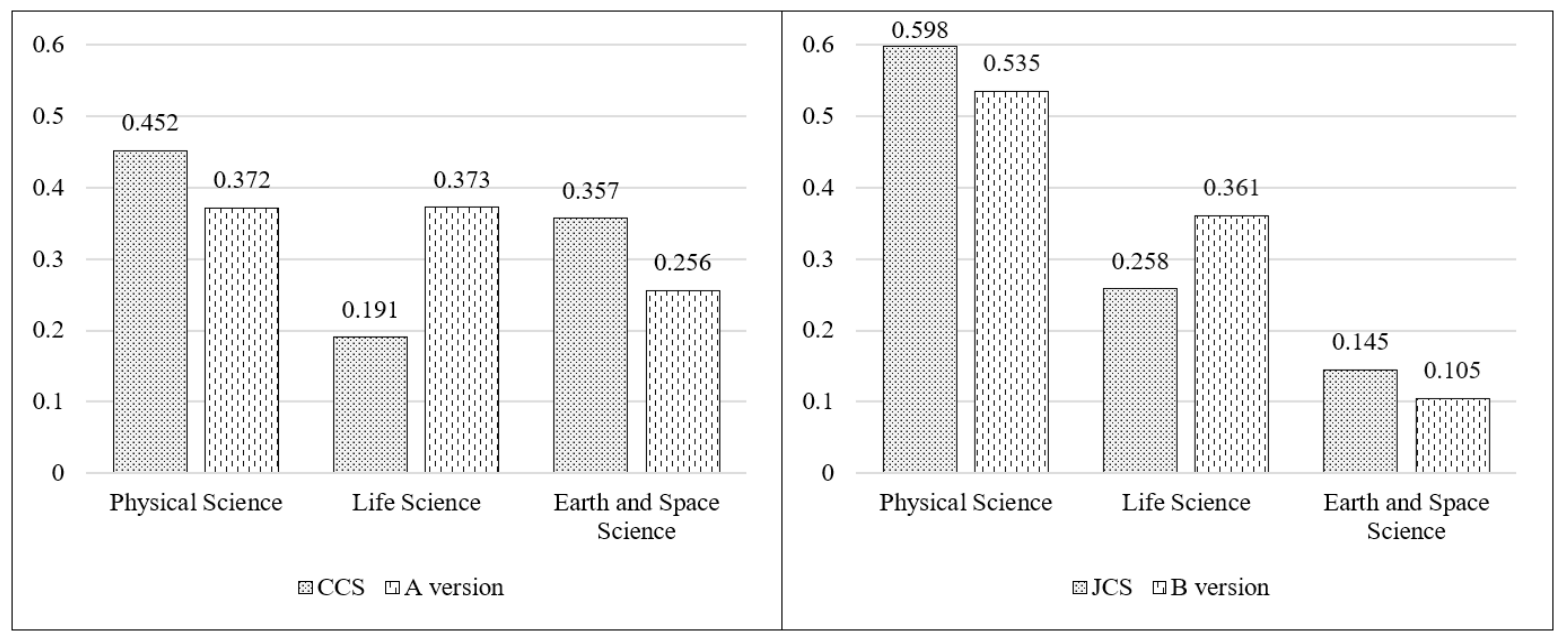

\section{Comparison of Alignment from the Cognitive Demand}

Figure 2 shows the alignment between science textbooks and their corresponding curriculum standards at different cognitive demands. In the figure, the abscissa represented the six cognitive demands, and the ordinate was the ratio of the cognitive demand in the whole content. It was found that under certain condition that there were no requirements of analysis and evaluation in the curriculum standards of two countries, the $B$ version did not involve the two cognitive demands, which kept the same with the curriculum standard, but the $A$ version involved the requirements of these two cognitive demands, which appeared different with the curriculum standard. Moreover, it is worth noting that the A version in the two lower cognitive demands named remembering and understanding did not reach the ratio of curriculum standard's requirements, and in the rest of the four higher cognitive demands went beyond the ratio of the curriculum standard's requirements. In other words, the $A$ version put forward higher requirements than curriculum standards for students in cognitive demand, while the B version did not reflect this trend.

\section{Figure 2}

The Ratios of the Chinese Curriculum Standard (CCS) and the A Version Textbook, the Japanese Curriculum Standard (JCS) and the $B$ Version Textbook in the Cognitive Demand Dimension

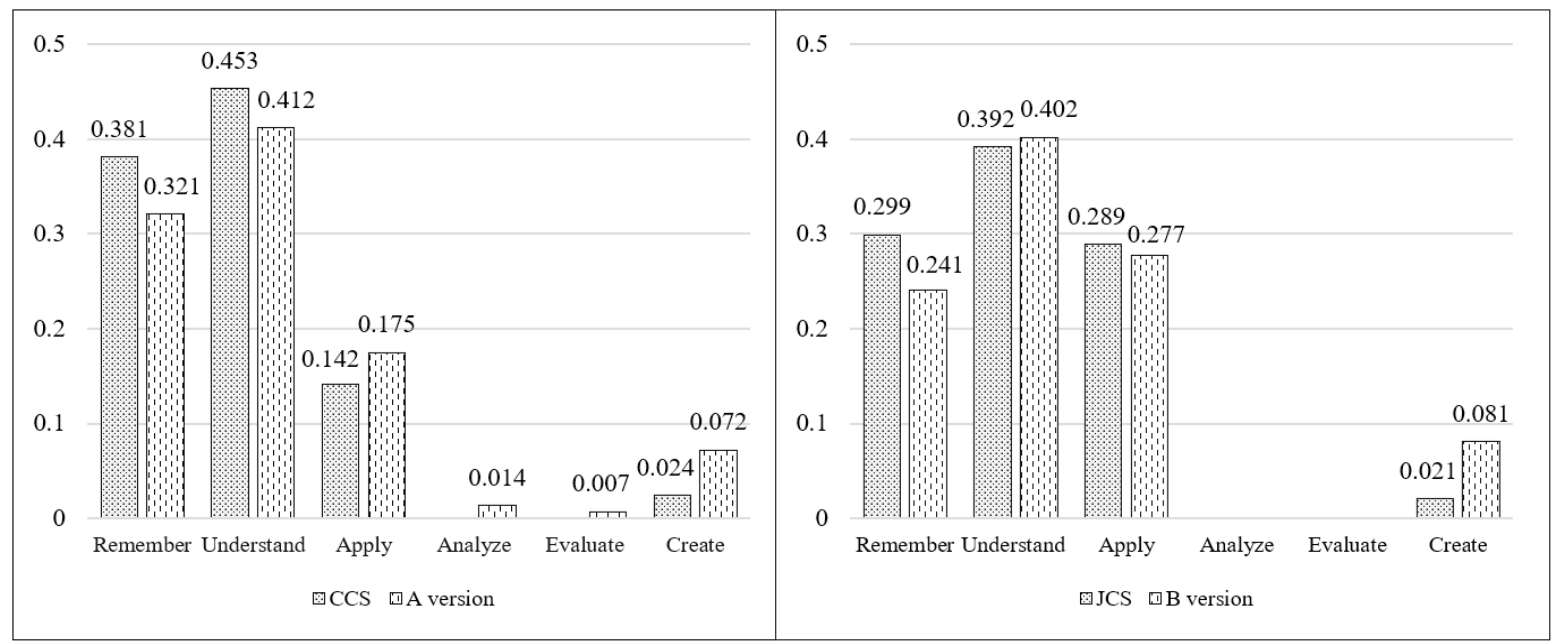




\section{Comparison of Alignment from the Emphasis}

Transformed each two-dimensional table into a content map, the emphasis of curriculum standards and textbooks was further analysed. Figure 3 and Figure 4 show the emphasis of the science curriculum standards and the textbooks of two countries. In figures, the abscissa axis for six cognitive demands, the ordinate axis for three topics, the place transverse and longitudinal axes intersect means the ratio of a certain cognitive demand of this topic in the overall context. Different patterns represented the different ratios, such as the light-coloured dot areas represented the highest ratio, which was between 0.2 to 0.25 ; the dark vertical stripe areas were the higher part between 0.15 to 0.2 ; the grid areas meant the moderate part between 0.1 to 0.15 ; the lower ratio of the dark dotted line areas was from 0.05 to 0.1 ; the white areas represented the least ratio less than 0.05 .

Combined the content maps with the data in the two-dimensional ratio tables, it was found that the B version and the Japanese curriculum standard both focused on the demand of understanding of physical science. However, although the Chinese curriculum standard exceeded the demand of remembering in physical science the most, but the A version shifted the focus to the demand of understanding in physical science, which virtually increased the demand for students' cognitive level. Besides, although in the A version the ratio of understanding level in physical science was higher, but the high level was not obvious, indicating that the A version was not in accordance with the requirements of the Chinese curriculum standard to stress the key point, but spread out the key contents.

\section{Figure 3}

The Emphasis of the Chinese Curriculum Standard (CCS) and the A Version Textbook

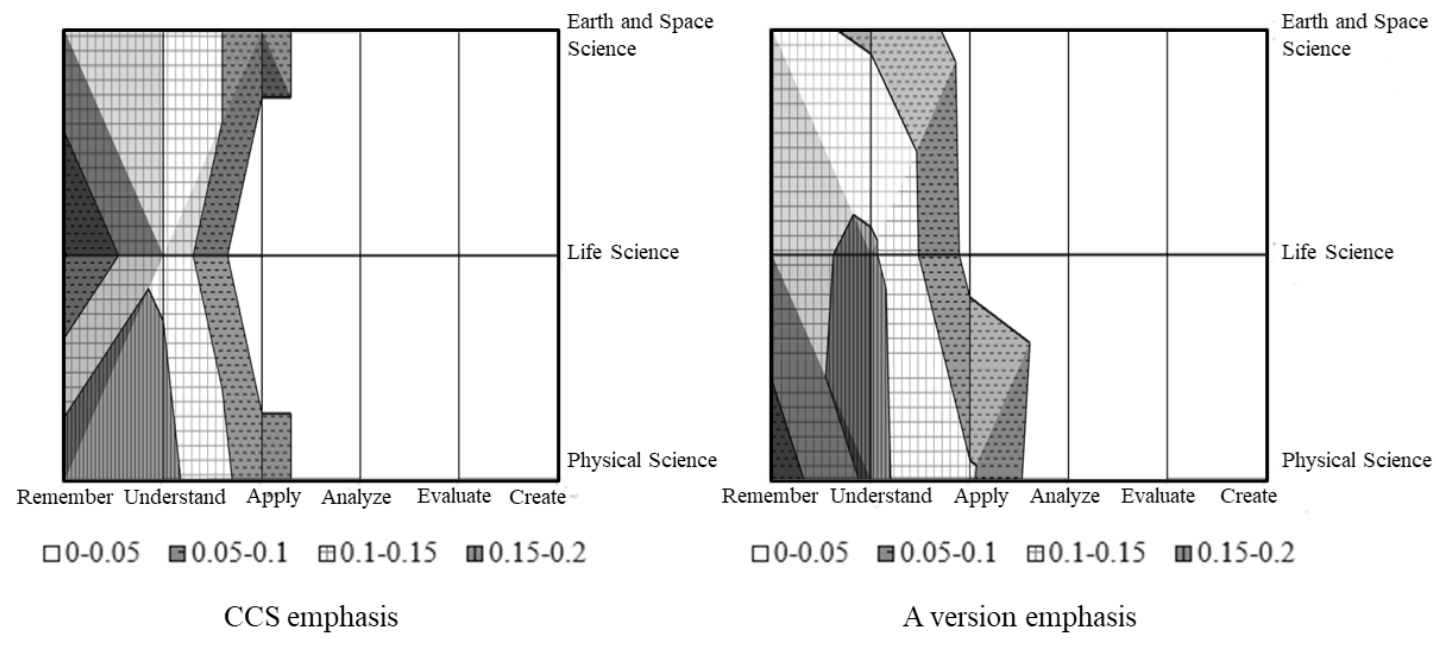

\section{Figure 4}

The Emphasis of the Japanese Curriculum Standard (JCS) and the B Version Textbook
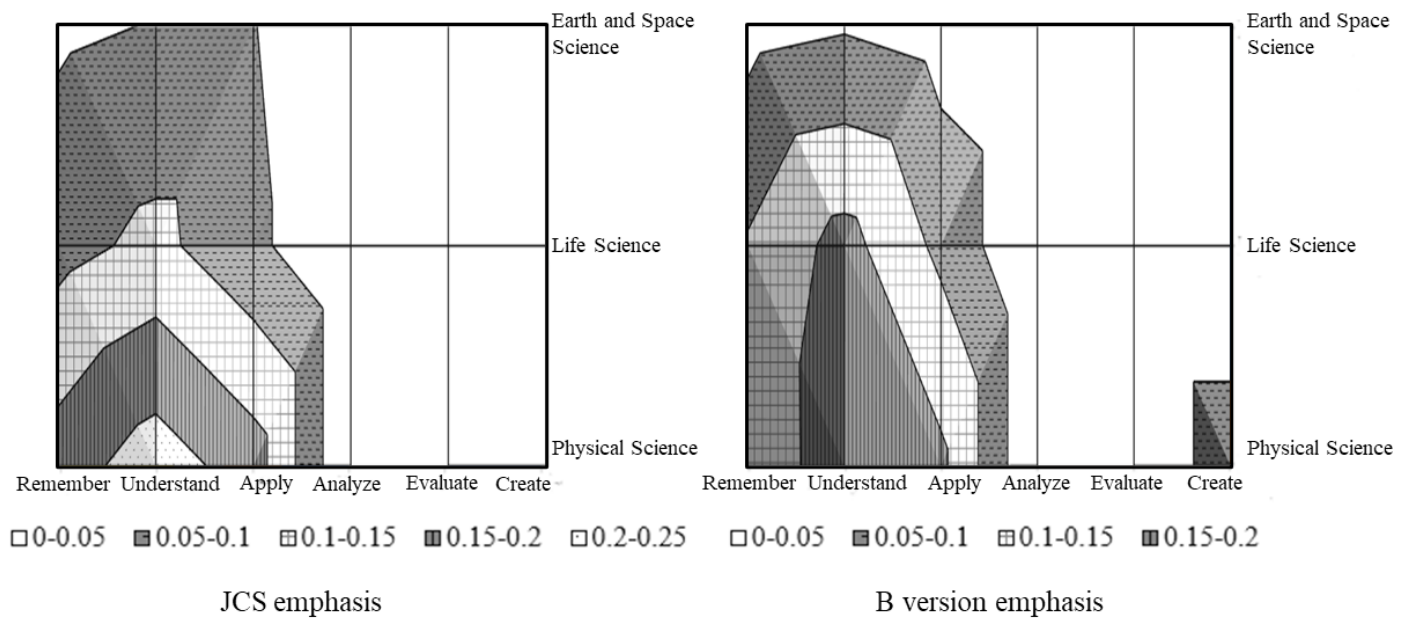


\section{Discussion}

Based on the theory of Anderson's taxonomy, this study localized the Porter's alignment model to make it more suitable for the alignment analysis between primary school science textbooks and curriculum standards. After deeply studying the new version of primary school science curriculum standards and representative textbooks in China and Japan, the texts according to the two-dimensional framework were coded. Although researchers have already used the alignment model to conduct an international comparative study of the alignment level between standardized tests and curriculum standards, also whether science textbooks in accordance with the requirement of curriculum standard have been discussed, in the existing study of science textbooks, there is still a lack of research on comparing the alignment level between textbooks and curriculum standards in different countries by using alignment model. This study provides a constructive reference for improving the alignment level between science textbooks and curriculum standards through data analysis and international comparison.

First, there is significant alignment between the B version and the Japanese curriculum standard, but there is no significant alignment between the $A$ version and the Chinese curriculum standard. This indicates that compared with the $B$ version, the $A$ version does not well implement the requirements of curriculum standard in the compilation process and does not form a high level of agreement with the curriculum standard. In view of this result, in the process of the revision and compilation of the A version in the future, it is necessary to deeply study the curriculum standards, carefully analyse where the current textbooks are inconsistent with the curriculum standards, and ensure that the textbooks and the curriculum standards achieve a higher degree of alignment.

Second, the main reason why the A version does not have a high degree of alignment in the topic dimension is that the content of life science is too much, while the content of earth and space science is reduced. This phenomenon also exists in the B version, showing that this is a common problem. Perhaps because textbook writers think that the topic of life science is easier to arrange outdoor observation inquiry activities, while designing the links that can closely contact with the natural environment, can make students engage their senses better, arouse curiosity and interest in learning science, and cultivate the ability of appreciation and aesthetic (Hecht et al., 2019; Jung et al., 2019; Merritt \& Bowers, 2020). However, this does not mean that the content of earth and space science can be reduced. Because the study of earth and space science is closely related to the development of students' spatial perception (Aliman et al., 2019; Park et al., 2009), and the middle grade in primary school is an important stage for students to develop spatial perception (Wang et al., 2007). Therefore, when arranging topics of textbooks, textbook writers should be in strict accordance with the curriculum standards for the division of different topics, to ensure that there will not be the ratio of one topic far beyond the curriculum standards, especially for the topic setting of life science and earth and space science, should be paid special attention to.

Third, "Beyond-standards" is a prominent problem in the science textbooks of the A version. Compared with the $B$ version, which carefully follows the requirements of the curriculum standard in the dimension of cognitive demand, it is shown that the A version has exceeded the requirements of the curriculum standard in the setting of the cognitive demand, no matter the content of the lower level of cognitive demands is reduced, the content of the higher level of cognitive demands is added, or the emphasis is shifted. There are two possible explanations for this phenomenon. From a historical perspective, China learned from the Soviet Union's experience in developing science education in the early years of founding, which present the characteristics of high difficulty of knowledge and heavy learning tasks (Cai, 2009). Although with the development of science education, attaching great importance to the independent exploration, highlighting the interesting and inspiring, emphasizing the students' subjectivity and other new features stand out gradually, but the historical factors more or less affect the current textbook writing. From a realistic point of view, the exam-oriented culture has a deep impact on the current education environment in China (Deng et al., 2020). In order to "win at the starting line", students are often expected to learn more and more difficult knowledge, which may prompt the textbook writers to intentionally increase the requirements on students' cognitive demands. However, as Piaget pointed out in his theory of cognitive development, children's cognitive development is a continuous and cumulative process, in which each step of development builds on the previous steps (Wadsworth, 1984). It reminds textbook writers that textbooks should not go beyond children's cognitive development level and blindly pursue advanced development. In fact, China's relevant policies have also strengthened the control of the phenomenon of "Beyond-standards". The Ministry of Education issued the "Negative List of Beyond-standard Training in Compulsory Education" in 2020 (The State Council of the People's Republic of China, 2020), requiring serious investigation and punishment of training behaviours exceeding the standard, and effectively reducing the overweight extracurricular burden of primary and secondary school students. It can be seen that following the law of students' cognitive development and setting the content with reasonable adjustment step by step have become an urgent need to improve the current science textbooks for primary schools in China. 
Finally, the alignment between textbooks and curriculum standards emphasized does not mean that there is no opportunity for the textbooks to show the features. It is not in conflict between following the requirements of curriculum standards and pursuing the innovation and characteristics of textbooks. The B version not only follows the curriculum standard, but also integrates the wisdom and ideas of the textbook writers. For example, as the content of "growth of plants", it was found that in the B version, the content is arranged according to time order. More specifically, the activity of sowing seeds is arranged in April, since the plants need a period to grow, students learn the knowledge of roots, stems, and leaves of plants in June, learn the knowledge of blossom in July, and observe the growth of fruits and the state of withering plants in September. This design is taken into full consideration of the reality and teaching pace. In contrast, the A version is more likely to set these links in a unit, which makes students need to complete the study of this unit within a few weeks. It seems to have a logical system, but in fact it does not follow the law of natural growth, which also brings some troubles to teachers in teaching. Therefore, ensuring a high alignment between science textbooks and curriculum standards is only the basic requirement in the process of compilation. It is an important task that primary school science textbooks should be paid more attention to constantly enrich and improve the details and integrate advanced ideas and unique wisdom into every corner of textbooks in the future.

\section{Conclusions and Implications}

In this study, the Porter's model was used to analyse the alignment of the third-grade primary school science textbooks with their corresponding curriculum standards, and the results were discussed from the perspectives of topic, cognitive demand, and emphasis. It was found that the alignment between the A version and the Chinese curriculum standard was lower, which needed to be further improved. The B version performed better at the alignment level, but there were also some places for further improvement. Besides, keeping proper control of the proportion of life science, fully following students' cognitive development levels and avoiding the problem of "Beyond-standards", highlighting the key content of curriculum standard stressed, being aligned with the curriculum standard based on the integrated into the characteristic and wisdom, are all needs to be paid attention to in the process of writing science textbooks.

This study has developed and supplemented the existing research on science textbooks by calculating and comparing the alignment between the two versions of primary school science textbooks and their corresponding curriculum standards in China and Japan. It has been found that there are similarities and differences in the alignment between the two versions of textbooks and curriculum standards. It can be seen that it is meaningful to explore the alignment between science textbooks and curriculum standards in different countries. On the one hand, it will help own country to find out in what aspects the science textbooks can further improve the level of alignment with curriculum standards, on the other hand, countries can also refer to each other's textbooks for points that align with curriculum standards. In addition, other countries with similar educational backgrounds can also get some inspiration.

The current research focuses on whether science textbooks and curriculum standards are aligned, and what are the misaligned points that need to be improved. In the future research, some interviews can be added. As a matter of fact, the compilers of curriculum standards and textbooks are not the same group. The problems that what kind of differences exist in their ideas of science education, how these differences will affect the alignment of science textbooks and curriculum standards, and what kind of impact they will have on science education, need to be further understood and discussed through in-depth interviews with the compilers of curriculum standards and science textbooks.

\section{Acknowledgements}

This work was supported by the financial supports by Key Projects of Philosophy and Social Sciences Research of Ministry of Education of China [grant numbers 18JZD017].

\section{Declaration of Interest}

Authors declare no competing interest.

\section{References}

Abd-El-Khalick, F., Waters, M., \& An-Phong, L. (2008). Representations of nature of science in high school chemistry textbooks over the past four decades. Journal of Research in Science Teaching, 45(7), 835-855. https://doi/abs/10.1002/tea.20226 
Aldahmash, A. H., Mansour, N. S., Alshamrani, S. M., \& Almohi. S. (2016). An analysis of activities in Saudi Arabian middle school science textbooks and workbooks for the inclusion of essential features of inquiry. Research in Science Education, 46, 879-900. https://doi.org/10.1007/s11165-015-9485-7

Aliman, M., Budijanto., Sumarmi., Astina, I. K., Putri, R. E., \& Arif, M. (2019). The effect of earthcomm learning model and spatial thinking ability on geography learning outcomes. Journal of Baltic Science Education, 18(3), 323-334. https://doi.org/10.33225/jbse/19.18.323

Andersen, K. N. (2020). Assessing task-orientation potential in primary science textbooks: Toward a new approach. Journal of Research in Science Teaching. 57(4),481-509. https://doi.org/10.1002/tea.21599

Anderson, L. W., \& Krathwohl, D. R. (2001). A taxonomy for learning, teaching, and assessing: A revision of bloom's taxonomy of educational objectives. Longman.

Cai, H. (2009). Science teaching theory in primary school. Hunan Science \& Technology Press.

Çakici, Y. (2012). Exploring Turkish upper primary level science textbooks' coverage of scientific literacy themes. Eurasian Journal of Educational Research, 49, 81-102.

Contino, J. (2013). A case study of the alignment between curriculum and assessment in the New York State earth science standardsbased system. Journal of Science Education and Technology, 22(1), 62-72. https://doi.org/10.1007/s10956-012-9376-x

Deng, L., Wu, S., Chen, Y., \& Peng, Z. (2020). Digital game-based learning in a Shanghai primary-school mathematics class: A case study. Journal of Computer Assisted Learning, 36(5), 709-717. https://doi.org/10.1111/jcal.12438

FitzPatrick, B., Hawboldt, J., Doyle, D., \& Genge, T. (2015). Alignment of learning objectives and assessments in therapeutics courses to foster higher-order thinking. American Journal of Pharmaceutical Education, 79(1), Article 10. https://doi.org/10.5688/ajpe79110

Fulmer, G. W., Tanas, J., \& Weiss, K. A. (2018). The challenges of alignment for the Next Generation Science Standards. Journal of Research in Science Teaching, 55(7), 1076-1100. https://doi.org/10.1002/tea.21481

Gilavand, A., Moosavi, A., Gilavand, M., \& Moosavi, Z. (2016). Content analysis of the science textbooks of Iranian junior high school course in terms of the components of health education. International Journal of Pediatrics, 4(12), 4057-4069. https://doi.org/10.22038/ijp.2016.7428

Hecht, M., Knutson, K., Crowley, K. (2019). Becoming a naturalist: Interest development across the learning ecology. Science Education, 103(3), 691-713. https://doi.org/10.1002/sce.21503

Hill, H. C. (2001). Policy is not enough: Language and the interpretation of state standard. American Educational Research Journal, 38(2), 289-318.

Jung, Y. J., Zimmerman, H.T., \& Land, S. M. (2019). Emerging and developing situational interest during children's tablet-mediated biology learning activities at a nature center. Science Education, 103(4), 900-922. https://doi.org/10.1002/sce.21514

Li, X., Tan, Z., Shen, J., Hu, W., Chen, Y., \& Wang, J. (2020). Analysis of five junior high school physics textbooks used in China for representations of nature of science. Research in Science Education, 50, 833-844. https://doi.org/10.1007/s11165-018-9713-Z

Li, X., Wang, L., Shen, J., Wang, J., Hu, W., Chen, Y., \& Tian, R. (2018). Analysis and comparison of scientific inquiry activities in eightgrade physics textbooks in China. Journal of Baltic Science Education, 17(2), 229-238. https://doi.org/10.33225/jbse/18.17.229

Liang, L. L., \& Yuan, H. (2008). Examining the alignment of Chinese national physics curriculum guidelines and 12th-grade exit examinations: A case study. International Journal of Science Education, 30(13), 1823-1835. http://dx.doi.org/10.1080/09500690701689766

Lin, C. (2011). Learning and development: The development and cultivation of mental ability of primary and middle school students. Beijing Normal University Publishing Group.

Liu, X., Zhang, B., Liang, L. L., Fulmer, G., Kim, B., \& Yuan, H. (2009). Alignment between the physics content standard and the standardized test: A comparison among the United States-New York State, Singapore, and China-Jiangsu. Science Education, 93(5), 777-797. https://doi/abs/10.1002/sce.20330

Lu, Q. \& Liu, E. (2012). Alignment between high school biology curriculum standard and the standardised tests of four provinces in China. Journal of Biological Education, 46(3), 149-164. https://doi.org/10.1080/00219266.2011.645855

Merritt, E. G., \& Bowers, N. (2020). Missed opportunities for observation-based ecology in the Next Generation Science Standards. Science Education, 104(4), 619-640. https://doi.org/10.1002/sce.21572

Ministry of Education, Culture, Sports, Science and Technology-Japan. (2015). A school guide for foreign children. https://www.mext.go.jp/a_menu/shotou/clarinet/003/1320860.htm

Ministry of Education, Culture, Sports, Science and Technology-Japan. (2019). A survey of international education trends in mathematics and science. https://www.mext.go.jp/a_menu/shotou/gakuryoku-chousa/sonota/detail/1344312.htm

Ministry of Education, Culture, Sports, Science and Technology-Japan. (2020). PISA (OECD A survey of students' learning attainment). https://www.mext.go.jp/b_menu/toukei/data/pisa/index.htm

Ministry of Education, Culture, Sports, Science and Technology-Japan. (2017). Primary school study guide essentials. https://www.mext.go.jp/a_menu/shotou/new-cs/1383986.htm

Ministry of Education, Culture, Sports, Science and Technology-Japan. (2019). Summary of the deliberations of the education curriculum council. https://www.mext.go.jp/content/1292164_1.pdf

Ministry of Education of the People's Republic of China. (2019). Compulsory education law of the People's Republic of China. Retrieved from http://www.npc.gov.cn/npc/c30834/201901/21b0be5b97e54c5088bff17903853a0d.shtml

Ministry of Education of the People's Republic of China. (2001). Notice on the issuance of the Outline of Curriculum Reform for Basic Education. http://www.moe.gov.cn/srcsite/A26/jcj_kcjcgh/200106/t20010608_167343.html

Ministry of Education of the People's Republic of China. (2017). Science curriculum standards for primary schools in compulsory education. Beijing Normal University Publishing Group. 
Newton, J. A., \& Kasten, S. E. (2013). Two models for evaluating alignment of state standards and assessments: Competing or complementary perspectives? Journal for Research in Mathematics Education, 44(3), 550-580. http://www.jstor.org/stable/10.5951/jresematheduc.44.3.0550

Park, M., Park, D. Y., \& Lee, R. E. (2009). A comparative analysis of earth science curriculum using inquiry methodology between Korean and the U.S. textbooks. Eurasia Journal of Mathematics, Science \& Technology Education, 5(4), 395-411.

Polikoff, M. S. (2015). How well aligned are textbooks to the common core standards in mathematics? American Educational Research Journal, 52(6), 1185-1211. https://doi.org/10.3102/0002831215584435

Polikoff, M. S., Zhou, N., \& Campbell, S. E. (2015). Methodological choices in the content analysis of textbooks for measuring alignment with standards. Educational Measurement, 34(3), 10-17. https://doi.org/10.1111/emip.12065

Porter, A. C. (2002). Measuring the content of instruction: Uses in research and practice. Educational Researcher,31(7), 3-14. https://doi.org/10.3102/0013189X031007003

Porter, A. C., Blank, R., \& Zeidner, T. (2007). Alignment as a teacher variable. Applied Measurement in Education,20(1), $27-51$. https://doi.org/10.1080/08957340709336729

Qhibi, A.D., Dhlamini, Z.B., \& Chuene, K. (2020). Investigating the strength of alignment between senior phase mathematics content standards and workbook activities on number patterns. Pythagoras, 41(1), 1012-2346. https://doi.org/10.4102/pythagoras.v41i1.569

Røthing, A. (2017). Sexual orientation in Norwegian science textbooks: Heteronormativity and selective inclusion in textbooks and teaching. Teaching and Teacher Education, 2017 (67), 143-151. https://doi.org/10.1016/j.tate.2017.06.005

Rothman, R., Slattery, J. B., Vranek, J. L. \& Resnick, L. B. (2002). Benchmarking and alignment of standards and testing. Center for the Study of Evaluation, National Center for Research on Evaluation, Standards, and Student Testing, Graduate School of Education \& Information Studies, University of California.

The State Council of the People's Republic of China. (2020). Circular of the general office of the ministry of education on the issuing of the Negative List of Beyond-standard Training in Compulsory Education. http://www.gov.cn/zhengce/zhengceku/2020-05/11/content_5510519.htm

Troia, G. A., Olinghouse, N. G., Zhang, M., Wilson, J., Stewart, K. A., Mo, Y., \& Hawkins, L. (2018). Content and alignment of state writing standards and assessments as predictors of student writing achievement: an analysis of 2007 National Assessment of Educational Progress data. Reading and Writing, 31(4), 835-864. https://doi.org/10.1007/s11145-017-9816-3

Tian, H. (2015). Basic education in Japan. Tongji University Press.

Vojirí, K., \& Rusek, M. (2021). Preferred chemistry curriculum perspective:Teachers' perception of lower-secondary school textbooks. Journal of Baltic Science Education, 20(2), 316-331. https://doi.org/10.33225/jbse/21.20.316

Wadsworth, B. J. (1984). Piaget's theory of cognitive and affective development. Longmen.

Wang, G., Ye, Z., \& Lin, C. (2007). Psychology of primary school children. Zhejiang Education Publishing House.

Webb, N. L. (1999). Alignment of science and mathematics standards and assessments in four states. National Institute for Science Education, University of Wisconsin-Madison, Council of Chief State School Officers.

Yacoubian, H. A., Al-Khatib, L., \& Mardirossian, T. (2017). Analysis of the image of scientists portrayed in the Lebanese national science textbooks. Science \& Education, 26, 513-528. https://doi.org/10.1007/s11191-017-9908-0 